\title{
Notes on wild dog Lycaon pictus and lion Panthera leo population trends during a drought in the Kruger National Park
}

\author{
M.G.L. MILLS
}

\begin{abstract}
Mills, M.G.L. 1995. Notes on wild dog Lycaon pictus and lion Panthera leo population trends during a drought in the Kruger National Park Koedoe 38(1): 95-99. Pretoria. ISSN 0075-6458.

Wild dog Lycaon pictus and lion Panthera leo populations in the Kruger National Park appeared to undergo an increase during a drought period in the early 1990s. Newly established packs, high adult survival and pup productivity contributed to an increase in the wild dog population and evidence for high predation success during the height of the drought is presented. An increase in the lion density between 1989 and 1993 on the northern basalt plains, as well as changes in the structure of the population, seem to be related to changes in prey populations, particularly to a decline in numbers and condition of buffalo Syncerus cafer.
\end{abstract}

M.G.L. Mills, National Parks Board, Private Bag X402, Skukuza, 1350.

\section{Introduction}

During 1991/1992 the Kruger National Park (KNP) experienced the severest drought in its recorded history (Zambatis \& Biggs 1995).

Whereas herbivorous animals usually decline in number during droughts (Walker et al. 1987), carnivores might be expected to respond differently. Their prey will be in poor condition and therefore easier to kill, so that, at least initially, there might be an increase in food availability, which in turn might lead to an increase in carnivore numbers. Furthermore, changes in vulnerability of different prey species might occur.

Carnivore population trends are difficult to monitor in the KNP as it is impossible to employ the aerial census techniques used to count herbivores (Joubert 1983). Nevertheless, ongoing research projects on wild dogs Lycaon pictus in the southern district and lions Panthera leo on the basalt plains north of Shingwedzi give an indication of the manner in which the populations of these carnivores responded to the drought. Elsewhere (Mills et al. 1995), the response of lion predation patterns to rainfall is discussed.

\section{Wild dog}

The wild dog sub-population in the area south of the Sabie River has been closely studied and monitored since the beginning of 1990. Each pack in the study area has been radio collared and the composition documented monthly. From 1990 until January 1993 there was a steady increase in wild dog numbers, reaching a peak in January 1993 (Table 1) after a series of dry years including the 1991/92 drought referred to above (Table 2).

The initial increase in the wild dog sub-population was due to the formation of three new packs (Gomondwane, Mbyamiti and Newu) during 1990 (Table 1), a comparatively dry year compared with 1989 which had been a high rainfall year. During the next 
Table 1

The minimum number (adults - pups) of wild dogs in packs in the southern district of the KNP, $1990-1993$

\begin{tabular}{|c|c|c|c|c|c|c|c|c|c|}
\hline Pack & Jan 1990 & July 1990 & Jan 1991 & July 1991 & Jan 1992 & July 1992 & Jan 1993 & July 1993 & Jan 1994 \\
\hline Skukuza & $18(11-7)$ & $29(11-18)$ & $13(8-5)$ & $27(10-17)$ & $8(3-5)$ & $6(6-0)$ & $7(7-0)$ & $3(3-0)$ & $4(4-0)$ \\
\hline Pretoriuskop & $13(7-6)$ & $14(6-8)^{*}$ & $11(5-6)$ & $24(7-17)$ & $17(7-10)$ & $26(14-12)$ & $16(8-8)$ & - & - \\
\hline Doispane & $13(9-4)$ & $21(8-13)^{*}$ & $14(7-7)$ & $25(9-16)$ & $8(6-2)$ & $27(9-18)$ & $23(8-15)$ & $38(21-17)$ & $30(14-16)$ \\
\hline Afsaal & $16(9-7)$ & $12(12-0)$ & $9(9-0)$ & $15(9-6)^{*}$ & $13(9-4)$ & $25(12-13)^{*}$ & $22(9-13)$ & $45(22-23)$ & $42(19-23)$ \\
\hline Crocodile Bridge & $7(5-2)^{*}$ & $7(7-0)$ & $6(6-0)$ & $6(6-0)$ & $5(5-0)^{*}$ & $13(5-8)^{*}$ & $13(5-8)^{*}$ & $?$ & $?$ \\
\hline Gomondwane & - & $13(4-9)$ & $8(3-5)$ & $14(7-7)^{*}$ & $10(9-1)$ & $4(4-0)$ & $6(6-0)$ & $15(5-10)^{*}$ & $12(4-8)$ \\
\hline Mbyamiti & - & $21(5-16)$ & $8(4-4)$ & $13(6-7)$ & $10(6-4)$ & $19(6-13)$ & $15(5-10)$ & $19(12-7)^{*}$ & $14(10-4)$ \\
\hline Nwaswitshaka & - & $5(5-0)$ & $5(3-2)$ & - & - & - & - & - & - \\
\hline Newu & - & - & $5(5-0)$ & $13(5-8)^{*}$ & $10(5-5)$ & $19(9-10)^{*}$ & $11(9-2)$ & $11(5-6)^{*}$ & $6(4-2)$ \\
\hline Thekwane & - & - & - & - & - & $8(2-6)^{*}$ & $7(2-5)$ & $6(6-0)$ & $4(4-0)$ \\
\hline Matjulu & - & - & - & - & - & - & $3(3-0)$ & - & - \\
\hline Nomad & - & - & - & - & - & 3 & 1 & 2 & - \\
\hline \multicolumn{10}{|l|}{ Total Southern } \\
\hline District & $67(40-27)$ & $122(58-64)$ & $79(50-29)$ & $124(50-78)$ & $81(50-31)$ & $150(70-80)$ & $124(63-61)$ & $139(76-63)$ & $112(59-53)$ \\
\hline
\end{tabular}

* Minimum number, i.e. exact composition of the pack was not determined.

two years 1991 and 1992 adult survival rates were particularly high (Table 2 ). Moreover, more pups were produced in 1991 and 1992 than in the other years (Table 1).

Evidence that wild dogs obtained more food during the height of the drought is given in Table 3 which shows a significant difference between the frequencies with which dogs were located on kills between November 1991 and October 1992, when the mean rainfall from the four rain stations in the area was only $295 \mathrm{~mm}$, in comparison with other times $\left(\chi^{2}=9.02 ; d f=1 ; p<0.01\right)$.

Apart from increased food availability to wild dogs during dry periods the lack of cover might also be advantageous to them. Unlike stalking predators which rely heavily on cover for hunting success, dogs are cursorial hunters (Estes \& Goddard 1967), which probably benefit from fewer obstructions concealed in rank grass during dry times. Additionally it has been found that

Table 2

Mean anmual rainfall from four weather stations in the southern district of the KNP and the percentage of wild dogs over one year old that survived each year between 1990 and 1993

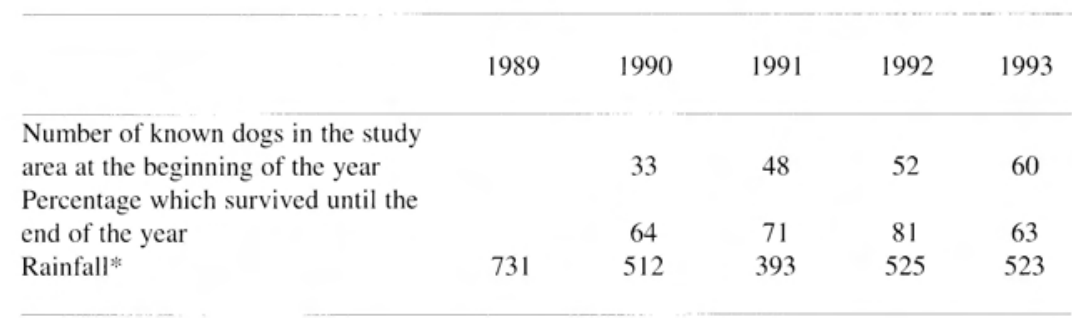

$*$ The long term mean for the four stations $=612.5 \mathrm{~mm}$. 
Table 3

Frequency with which wild dogs were located from the air on kills during the height of the drought in comparison with at other times

During the drought

(Nov 1991 - Oct 1992)
During other times
Number of tracking flights undertaken

Number of times dogs found feeding on a kill
57

10
215

11

when an average of only $295 \mathrm{~mm}$ rain was measured at four weather stations in the study area, and at during the study

lions are important predators of wild dogs (Mills \& Gorman in prep), so the more open habitat created during the drought may have lessened the chances of lions stalking up on wild dogs.

\section{Lion}

The lion population in the KNP also seems to have responded to the drought. The best evidence for this was gleaned on the basalt shrub mopani Colophospermum mopane plains north of Shingwedzi, where a survey of the lion population carried out in October 1993 using the technique developed by Smuts et al. (1977), showed a large increase in the number of lions in this area compared to a previous survey in 1989. A density of one lion per $8.9 \mathrm{~km}^{2}$, and one adult or subadult per $10.4 \mathrm{~km}^{2}$ was found in 1993 , compared with a density of one adult and subadult per $30 \mathrm{~km}^{2}$ found in the 1989 survey.

Not only were there more lions on the plains in 1993, the structure of the population was different to what had been previously found (Table 4). More adult males $\left(\chi^{2}=4.38 ; d f=1\right.$; $p<0.05)$ and fewer cubs $\left(\chi^{2}=8.30 ; d f=1\right.$; $p<0.01$ ) were encountered during the 1993 survey.

Prey populations on the northern plains have also undergone some dramatic changes since 1989. All four of the lion's major prey

Table 4

Sex ratios and age composition of lions from two surveys on the northern plains in the KNP

\begin{tabular}{|c|c|c|c|c|c|c|c|c|c|}
\hline \multirow[t]{2}{*}{ Survey } & \multicolumn{3}{|c|}{ Sex ratio (male:female) } & \multicolumn{6}{|c|}{ Age composition (\%) } \\
\hline & Adult & Subadult & $\begin{array}{l}\text { Adult \& } \\
\text { subadult }\end{array}$ & Adult & Subadult & $\begin{array}{l}\text { Large cub } \\
(7- \pm 15 \mathrm{~m})\end{array}$ & $\begin{array}{c}\text { Small cub } \\
(0-6 \mathrm{~m})\end{array}$ & $\begin{array}{l}\text { Adult \& } \\
\text { subadult }\end{array}$ & Cub \\
\hline $1989^{*}$ & $1: 2.25$ & - & 1:1.3 & - & $\cdot$ & 23.1 & 15.4 & 61.5 & 38.5 \\
\hline 1993 & $1: 1.1$ & $1: 1.2$ & $1: 1.1$ & 71.9 & 13.5 & 14.6 & 0 & 85.4 & 14.6 \\
\hline
\end{tabular}

* Adult and subadult females were not separated during this survey. 


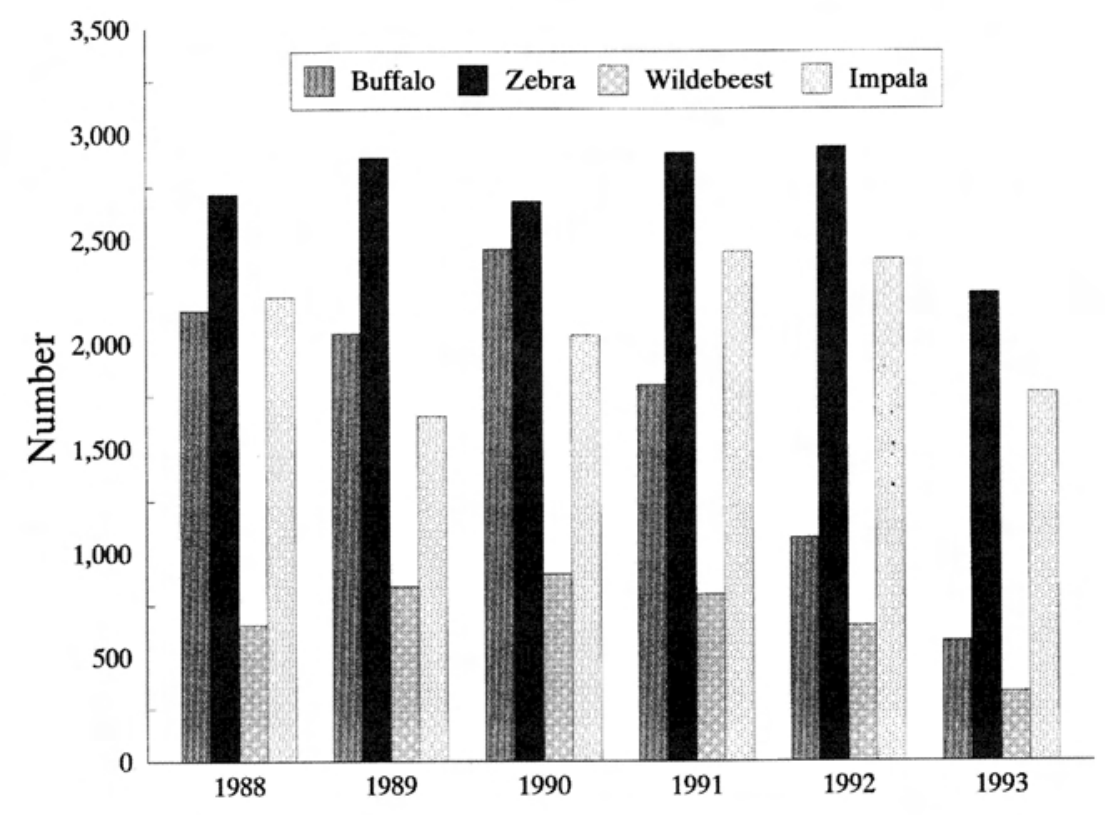

Fig 1. Numbers of buffalo, zebra, wildebeest and impala counted on the plains north of Shingwedzi during the annual ecological aerial surveys, $1988-1993$.

species in the KNP; impala Aepyceros melampus, zebra Equus burchellii, wildebeest Connochaetes taurinus and buffalo Syncerus cafer (Pienaar 1969; Mills et al. 1995 in press) have declined since 1990, the buffalo particularly so (Fig. 1). The drought, and in the case of buffalo also the anthrax epidemic of 1991, are the major causes for these declines. Due to the deteriorating condition of the buffalo in particular they became more vulnerable to predation (Mills et al. 1995 in press) and so the lions were presented with a greatly increased food supply. Male lions, in particular, seem to have capitalised on this situation, probably through increased survival and a tendency to stay in their natal territories because of the abundant food supply.

\section{Conclusions.}

The limited data presented here support the hypothesis that drought conditions benefit carnivores in the short term. A similar phenomenon was recorded in Mana Pools National Park, Zimbabwe with lions (Dunham 1992).

\section{References}

Dunham, K.M. 1992. Response of a lion (Panthera leo) population to changing prey availability. Journal of Zoology, London 227: 330-333.

ESTES, R.D. AND J. GodDARD. 1967. Prey selection and hunting behavior of the African wild dog. Journal of Wildlife Management 31: 52-70.

JOUBERT, S.C.J. 1983. A monitoring programme for an extensive national Park. Pp. 201-212. In: OWENSMITH, R.N. (ed.). Management of large mammals in African conservation areas. Pretoria: Haum. 
Mills, M.G.L., H.C. Biggs And I.J. Whyte. 1995 (in press). The relationship between lion predation, population trends in African herbivores and rainfall. Wildlife Research 22

PIENAAR, U. de V. 1969. Predator-prey relationships among the larger mammals of the Kruger National Park. Koedoe 12: 108-176.

Smuts, G.L., I.J. Whyte And T.W. Dearlove. 1977. A mass capture technique for lions. East African
Wildlife Journal 15: 81-87.

Walker, B.H., R.H. EMSlie, R.N. OWen-Smith, AND R.J. SCHOLES. 1987. To cull or not to cull: Lessons from a southern African drought. Journal of Applied Ecology 24: 381-401.

Zambatis, N. AND H.C. Biggs. 1995. Rainfall and temperature during the 1991/92 drought in the Kruger National Park. Koedoe 38(1):1-16. 